\title{
PHYSICOCHEMICAL PROPERTIES OF THE WATER DEPLETED OF HEAVY ISOTOPES
}

\author{
Vladislav V. Goncharuk \\ National Academy of Sciences of Ukraine, Kiev, Ukraine, A.V. Dumanskii Institute of Colloid and Water Chemistry, \\ 42, Vernadsky blvd. 03680, Kyiv, Ukraine, tel. 3804442401 96, fax 3804442382 24, \\ e-mail:honch@iccwc.kiev.ua
}

\begin{abstract}
Data on physicochemical properties of the light water (deuterium concentration is reduced to the ratio $\mathrm{D} / \mathrm{H}=4 \mathrm{ppm}$ and that of the isotope of oxygen 18 - to the ratio ${ }^{18} \mathrm{O} /{ }^{16} \mathrm{O}=750 \mathrm{ppm}$ ) have been obtained. They include the melting and boiling points, kinematic viscosity, density, the spin-spin proton relaxation time, self-diffusion coefficients, and the small-angle laser light scattering. An explanation was proposed for the detected significant changes of the light water as compared with the high-resistivity water having geochemically ordinary isotope composition. This explanation was based on the mechanism of formation of supramolecular density inhomogeneities in water representing the deuterium-stabilized heterophase clusters.
\end{abstract}

Keywords: Physicochemical properties of water, protium water, light water, heavy water, water toxicity

\section{Introduction}

Water as a chemical matter has no color, no taste, and no smell. Drinking water this is the water, whose organoleptic, physicochemical, and biological properties meets human biological needs and having neither color nor smell should have taste determined by the presence in it of physiologically necessary salts of calcium, magnesium, sodium, and potassium in corresponding concentrations without which metabolism in human organism is impossible.

Life on earth was revived thanks to the presence of water. The greatest secret is unknown origin on the Earth of genome. However, the emergence of the biological life, most likely, is determined by the presence of bacteria having space origin, which created a fruitful layer of soil and which still penetrate our earth from space together with space objects. Therefore, the appearance and development of biological variety on our planet is determined, mainly, by the presence of water unique by its physicochemical properties rather than the presence in it of various microorganisms capable of surviving under extreme conditions of the space. The unique properties of the water, we are accustomed of, belongs to one of the simplest and well studied substances, is determined by its isotope composition and, first of all, by the ratio of protium and deuterium. The natural concentration of deuterium in the world ocean, in salt and fresh waters varies within the interval $90-180 \mathrm{ppm}$. The stable optima; concentration of deuterium in water constitutes $150 \mathrm{ppm}$. It is within this concentration interval that our ordinary water possesses maximum biological activity both in sea and in fresh water bodies. A decrease or an increase of the deuterium concentration in water results in a radical change of its physicochemical and biological properties, namely: density, viscosity, refractive index in water, speed of sound in it and many other properties right to boiling and freezing points. Light water $(\sim 5 \mathrm{ppm})$ freezes and boils at temperature by $\sim$ $3{ }^{\circ} \mathrm{C}$ lower than the ordinary water in other standard conditions. The most astounding is that fact that both protium and deuterium water is toxic for biological life on earth. Therefore, in order to detect life on other planets like our, one has to find not simply water, but the water with the same ratio in it of deuterium and protium.

Natural water represents a multicomponent mixture of molecules of different isotope composition (isotopologues). In natural water one million molecules on average includes 997284 molecules of ${ }^{1} \mathrm{H}_{2}{ }^{16} \mathrm{O}, 311$ molecules of ${ }^{1} \mathrm{HD}^{16} \mathrm{O}, 390$ molecules of ${ }^{1} \mathrm{H}_{2}{ }^{17} \mathrm{O}$, and about 2005 molecules of ${ }^{1} \mathrm{H}_{2}{ }^{18} \mathrm{O}$ [1]. The concentration of water molecules containing heavy isotopes $\left(\mathrm{D},{ }^{17} \mathrm{O}\right.$, and $\left.{ }^{18} \mathrm{O}\right)$ in natural waters fluctuates within the limits established in two basic international standards for the isotope composition of hydrosphere: VSMOW (Vienna Standard Mean Ocean Water) and SLAP (Standard Light Antarctic Precipitation) introduced by the International Atomic Energy Agency (IAEA) [1, 2]. The VSMOW standard determines the isotope composition of the deep water of the world ocean, while the SLAP standard determines the isotope composition of the natural water from the Antarctic (deuterium concentration varies depending on the depth of ice and its location on the mainland within the limits of $\sim 10 \mathrm{ppm}$ ) at the current level on the surface equal to $\sim 90 \mathrm{ppm}$ (EDC station [3]). In accordance with the VSMOW standard the absolute contents of deuterium $\mathrm{D} /{ }^{1} \mathrm{H}$ and oxygen -18 $\left({ }^{18} \mathrm{O} /{ }^{16} \mathrm{O}\right)$ in the ocean water amount to $155.76 \pm 0.05$ and $2005.20 \pm 0.45 \mathrm{ppm}$, respectively, [4]. The content of the lightest isotopologue $\left({ }^{1} \mathrm{H}_{2}{ }^{16} \mathrm{O}\right)$ in the water corresponding in terms of the isotope composition to the VSMOW standard 
and the SLAP standard amount to 99.73 and 99.76 mol. \%, respectively. The SLAP standard characterizes the lightest natural water on Earth. Hence, the concentrations of deuterium $\mathrm{D} / \mathrm{H}$ and oxygen $-18\left({ }^{18} \mathrm{O} /{ }^{16} \mathrm{O}\right)$ in this water amount to 89 and 1894 ppm, respectively, [5]. The light water can be defined as follows: as a result of special treatment the share of the lightest isotopologue ${ }^{1} \mathrm{H}_{2}{ }^{16} \mathrm{O}$ in this water was increased as compared with standard SLAP.

The reason for designating the light water as deuterium-depleted was, probably, the fact that the most significant reduction of deuterium content was achieved by rectification in the process of removing heavy isotopologues and also due to technological difficulties of determining the content of oxygen isotopes. As shown in papers [6-8], "deuteriumdepleted water" as a particular case of the light water possesses pronounced antitumor properties. The light water speeds up the exchange processes (both, physicochemical and biological) resulting in different physiological effects: immunostimulating, reproductive, and also in changes of the receptor sensibility to catecholamine and angiotensin [9, $10]$.

It can be assumed that such important biological responses registered according to the results of experimental investigations must have at the bottom common reasons, to which primarily we should refer the variation of the physicochemical properties of water. That is why the present paper is devoted to determination of the classical "tabular" physicochemical parameters of the light water and the comparative description of results (for preparations of the light, natural and heavy waters) obtained by new methods of investigating the associated liquids.

\section{Materials and methods}

The deionized (high-resistivity) water $\left(18 \mathrm{M} \Omega \cdot \mathrm{cm}\right.$ at $\left.25^{\circ} \mathrm{C}\right)$ was prepared by subjecting the pyrogenic distilled water to purification on the Milli-Q system produced by Millipore, Great Britain. The light water was produced at OJSC Almaz by the vacuum rectification method. The content of deuterium $(\mathrm{D} / \mathrm{H})$ and oxygen $-18\left({ }^{18} \mathrm{O} /{ }^{16} \mathrm{O}\right)$ in light water amounted to 4 and $750 \mathrm{ppm}$, respectively, as compared with $\mathrm{D} / \mathrm{H}=140$ and ${ }^{18} \mathrm{O} /{ }^{16} \mathrm{O}=1966 \mathrm{ppm}$ for deionized water. The heavy water (99.9\%) corresponded to Technical Specifications TU 95-1893-89. As a result of the performed investigation using the atomic absorption spectrometry with electrothermal atomization and Zeeman background correction [11], such elements as $\mathrm{Al}, \mathrm{V}, \mathrm{Cr}, \mathrm{Mn}, \mathrm{Ni}, \mathrm{Fe}, \mathrm{Cu}, \mathrm{Zn}, \mathrm{As}, \mathrm{Cd}$, and $\mathrm{Pb}$ were not detected in any preparations of water (concentration $<0.1 \mathrm{nM}$; the detection limit was $0.1-10 \mathrm{nM}$ ).

In addition, the presence of impurity particles of the dispersed phase was not registered in the specified preparations of water by using the methods described in paper [12].

Determination of the isotope composition. The methods used for measuring the deuterium concentration included the mass-spectrometry method [13] and the method of multiple-pass laser absorption spectroscopy using an LWIA-24d instrument produced by Los Gatos Research, Inc. [14]. The content of oxygen-18 was also controlled by using the multiple-pass laser absorption spectroscopy. Density of water was measured by a digital densimeter of model LiquiPhysics Excellence DM45DR produced by Mettler Toledo, and also by using a PZh_2 picnometer in accordance with GOST 18995.1-73. The relative error of the method was $0.016 \% ; \mathrm{P}=0.95$.

Viscosity of water was determined by using a VPZh-2 capillary glass viscosimeter (capillary internal diameter of $0.56 \mathrm{~mm}$ ) with an additional thermostating device [15]. The relative error of the method was $0.89 \%$.

Boiling point of water was measured on the Sventaslavskii instrument [15].

Melting point of water was determined by the method of differential scanning calorimetry (DSC). The scanning speed was $4 \mathrm{deg} / \mathrm{min}$. The solution under investigation in the amount of $0.0010-0.0100 \mathrm{~g}$ was pressed into container and subjected to cooling with liquid nitrogen for one-two minutes to a temperature of $223 \mathrm{~K}$. It was assumed that at such high speeds of cooling the changes of its phase state will be minimum. Next, the system was held during several minutes at temperature $223 \mathrm{~K}$ for the establishment of equilibrium. Thermograms were registered in the interval 223-293 K. In order to determine the reproducibility of results of DSC

and their dispersions, 10 measurements were performed for each water sample. The calculated sample variance amounted to 0.012 .

Spin-spin relaxation time of water protons was determined by the NMR spin-echo method [16].

Molecular dynamics characteristics of water were determined by the method of monoenergetic neutron scattering (13.289 meV) [17]. In order to calculate the self-diffusion coefficients, the results were processed by using the Oskotskii-Ivanov model.

Variance analysis of water samples and nanoparticles was conducted by using the method of low-angle laser light scattering (LALLS) and the dynamic light scattering (DLS) (photon correlation spectroscopy) on instruments MasterSizer 2000 and ZetdSizer Nano ZS (Malvern Instruments) [11, 12].

Values of the $\boldsymbol{p H}$ were measured on a PP-20 pH-meter produced by Sartorius and equipped with a thermal sensor and by using the spectrophotometry with an acid-base indicator of phenol red $\left(\mathrm{pK}_{\mathrm{a}}=7.4\right)$ at the concentration $30 \mu \mathrm{M}[18]$. 


\section{Result and discussion}

Physicochemical properties of light water. It occurred that the "classical" physicochemical properties of the light water differ from the deionized water having natural isotope composition (Table 1). The differences is surface tension (at the water-air interface) for the light water-deionized water pair are comparable with such for the deionized water-heavy water pair. In terms of the parameter of kinematic viscosity the light water is closer to the deionized water of natural isotope composition than the deionized water to the heavy one. It should be stressed that the density of the light and deionized waters to a great extent is determined by the concentration of heavy isotopes of oxygen (see Table 1, line 3).

The temperatures of phase transitions in the light water are significantly reduced. The reduction of the freezing point of light water $\left(<-1^{\circ} \mathrm{C}\right)$ exceeds the similar value for a $100 \mathrm{mM}$ sodium chloride or saccharose solution. This apparent violation of the Raoult law as also the probable variation of the ebullioscopic constant of the light water (the boiling point is reduced by $7^{\circ} \mathrm{C}$ ) make it possible to suggest that the light water represents a new associated liquid that have not been earlier scientifically described in literature. It should be noted that the modern quantum mechanical models function by adopting during the simulation other physicochemical constants obtained for a real liquid heterogenetic in terms of isotope composition [19, 20].

Table 1

Physical properties of preparations having different isotope composition $\left(T=20 \pm 0.04^{\circ} \mathrm{C}\right)$

\begin{tabular}{|c|c|c|c|c|}
\hline $\begin{array}{l}\text { Item } \\
\text { No. }\end{array}$ & Parameter & $\begin{array}{c}\text { Light water } \\
\mathrm{D} / \mathrm{H}=\mathbf{4}\end{array}$ & $\begin{array}{c}\text { Deionized water having } \\
\text { natural isotope composition } \\
\mathrm{D} / \mathrm{H}=140\end{array}$ & $\begin{array}{l}\text { Heavy water } \\
99 \% \text { of } D_{2} O\end{array}$ \\
\hline 1 & Kinematic viscosity, $\mathrm{mm}^{2} / \mathrm{s}$ & 0.987 & 1.012 & 1.274 \\
\hline 2 & Surface tension, $\mathrm{mN} / \mathrm{m}$ & 75.172 & 72.860 & 67.800 \\
\hline 3 & Density, $\mathrm{g} / \mathrm{cm}^{3}$ & $0.99692 *$ & $0.99820 * *$ & 1.1042 \\
\hline 4 & Boiling point, ${ }^{\circ} \mathrm{C}$ & 93.7 & 99.9 & 101.4 \\
\hline 5 & Melting point, ${ }^{\circ} \mathrm{C}$ & $\begin{array}{l}\text { from }-4 \text { to } \\
-1 * * *\end{array}$ & 0 & 3.8 \\
\hline 6 & Time of spin-spin proton relaxation $\left(\mathrm{T}_{2}\right), \mathrm{s}$ & $0.347 \pm 0.024$ & $2.000 \pm 0.140$ & - \\
\hline 7 & $\begin{array}{l}\text { Contribution to the total self-diffusion } \\
\text { coefficient from collective movements }\left(D_{l}\right. \\
\left.\times 10^{9}\right), \mathrm{m}^{2} \mathrm{~s}^{-1}\end{array}$ & 0.63 & 0.46 & 0.52 \\
\hline 8 & $\begin{array}{l}\text { Contribution to the total self-diffusion } \\
\text { coefficient from single-particle movements } \\
\left(D_{l}+D_{f}=D \text { is the total self-diffusion }\right. \\
\text { coefficient }) \text {, } \\
\left(D f \times 10^{9}\right), \mathrm{m}^{2} \mathrm{~s}^{-1}\end{array}$ & 1.60 & 1.77 & 1.50 \\
\hline 9 & $\begin{array}{l}\text { Life time of molecules in the oscillating } \\
\text { state around the equilibrium center, }\left(\tau_{0}\right. \\
\left.\times 10^{12}\right), \mathrm{s}\end{array}$ & 2.08 & 2.80 & 2.79 \\
\hline
\end{tabular}

Notes: ${ }^{* 18} \mathrm{O} /{ }^{16} \mathrm{O}=757 \mathrm{ppm} ;{ }^{* * 18} \mathrm{O} /{ }^{16} \mathrm{O}=1966 \mathrm{ppm}\left(\right.$ at $\left.T= \pm 25^{\circ} \mathrm{C}\right) ; * * *$ depending on the weight of sample.

The variation of properties of liquid during the reduction of concentration of heavy isotopes testifies the presence of a "control" function of water molecules containing heavy isotopes: one molecule of ${ }^{1} \mathrm{H}_{2}{ }^{16} \mathrm{O}$, one molecule of ${ }^{1} \mathrm{H}_{2}{ }^{17} \mathrm{O}$ and $5-7$ molecules of ${ }^{1} \mathrm{H}_{2}{ }^{18} \mathrm{O}$ fall on $\sim 3000$ molecules of ${ }^{1} \mathrm{H}_{2}{ }^{16} \mathrm{O}$ [1]. Such realization of the isotope effect is possible via the cluster organization of associated liquid. The growing number of tie molecules in light water and its higher "homogeneity" in terms of the structure is corroborated by the variation of its molecular dynamics properties (see Table 1, lines 6-8). The diffusion coefficient increases in the light water reflecting the contribution from collective movements $\left(D_{l}=0.63 \times 10^{-9} \mathrm{~m} \mathrm{~s}^{-1}\right)$ as compared with the deionized water $\left(D_{l}=0.46 \times 10^{-9} \mathrm{~m} \mathrm{~s}^{-1}\right)$. The same tendency is also observed by the replacement of protium with deuterium in the preparation of heavy water.

A significant reduction of the spin-spin relaxation time $(0.35 \pm \pm \quad 0.02 \quad \mathrm{~s}$ versus $2.00 \pm 0.10 \mathrm{~s}$ for light and deionized water, respectively, (see Table 1, line 6) means a sharp reduction of the degrees of freedom in light water. The removal of deuterium, probably, results in the elimination of geometrical effects in the network of hydrogen bonds. The obtained results well agree with the reduction of the freezing point of the light water.

The possible mechanism of implementation of the isotope effect during the formation of the water having the natural isotope composition. In our view the causes of differences in the properties of the light and deionized water can be explained as follows. In earlier papers [21 - 26] we put forward a hypothesis on the formation in the water of natural 
isotope composition of density inhomogeneities of submillimeter range - deuterium-stabilized gigantic heterophase clusters (GHC) with the relaxation time of more than one second. It should be stressed that the long-living supramolecular density inhomogeneities (gigantic in comparison with the well known nanoclusters) were experimentally observed by other teams of researchers [27, 28]. These density inhomogeneities of water are stabilized by heavy isotopologues at their probable arrangement on the surface of density inhomogeneities that allows them to implement the "control" function.

As was noted in papers [21,23], the rise of water homogeneity in terms of the isotope composition leads to disintegration of GHC. The opposite statement is also true: formation of GHC in the light water is hampered. This is demonstrated by the performed experiment on induction of the GHC formation by latex nanoparticles. As for any dispersed formation in colloidal solution, a "primer" is required for formation of GHC. In measuring the dimensional spectra of density inhomogeneities by using the LALLS method [12] it is possible to register GHC of the submillimeter range induced by nanoparticles (the same preparation of water, where the solution of nanoparticles is introduced to, is used as a background). Table 2 shows that such induction of GHC formation is only possible in the water having the natural isotope composition.

Table 2

Initialization by latex nanoparticles of the formation of density inhomogeneities - gigantic heterophase clusters in water preparations of different isotope composition

\begin{tabular}{|c|c|c|}
\hline $\begin{array}{c}\text { True (certified) size of } \\
\text { nanoparticles, } \mathbf{n m}\end{array}$ & \multicolumn{2}{|c|}{ Measured size of density inhomogeneities in different solvents, $\mathbf{n m}$} \\
\cline { 2 - 3 } & light water & ordinary water \\
\hline 20 & $25 \pm 5$ & $10000 \pm 500$ \\
\hline 40 & $50 \pm 7$ & $10100 \pm 200$ \\
& & $26100 \pm 1000$ \\
\hline 80 & $85 \pm 7$ & $30100 \pm 900$ \\
\hline 35 & $315 \pm 5$ & $315 \pm 5$ \\
\hline 1200 & $1300 \pm 50$ & $1400 \pm 100$ \\
\hline Note. The concentration of sulfated nanoparticles (Invitrogen Corporation) amounts to
\end{tabular}

$0.00005 \mathrm{vol} \%$. All measurements were performed in the circulation mixing mode.

The analysis of suspensions of the standard latex microspheres of nanometer range by the method of low-angle laser light scattering revealed significant differencesz $3332 \mathrm{ds}$ in dimensional spectra with respect to standard values. Hence, for hydrophobic nanospheres having the diameter $<100 \mathrm{~nm}$ their diameters appear to be exceeded by orders of magnitude that can be explained by the initiation of the formation of water GHC by nanoparticles. The investigation of larger microparticles does not reveal any variations of dimensional spectra: the diameter coincides with the declared value.

In the light water new GHC are not initialized by nanoparticles. Sulfated latex particles having the size $>100$ $\mathrm{nm}$ do not result in formation of GHC. In separate experiments it was revealed that hydrophobic nanoparticles are more effective in respect of $\mathrm{GHC}$ induction, i.e. they induce the formation of latter at lower concentrations than the sulfated nanoparticles. The collection of the specified data makes it possible to assume that in addition to our earlier descriptions of the Kolmogorov mechanisms of the white cascade of dissipation of kinetic energy into thermal one [23], a considerable contribution to the formation of GHC can be made by the dispersion (Deryagin) interactions.

The reduced concentration of GHC in light water $[23,24]$ results in the formation of a liquid that is closer to the model of "continual" water having the reduced values of the temperature of phase transitions, viscosity, and enhanced surface tension. It is not excluded that the investigation of the properties of samples of the light water with a higher concentration of isotopologue ${ }^{1} \mathrm{H}_{2}{ }^{16} \mathrm{O}$ shall reveal further reduction of the melting and boiling points in the direction "specified" by the Mendeleev periodic law for hybrids of elements of the II period and VI group of the main subgroup.

\section{Conclusions}

On the basis of obtained data the following conclusions can be made:

1. In terms of a series of physicochemical properties the light water is a new associated liquid that has not been scientifically defined earlier.

2. Possible mechanism of implementing the "control" function of heavy isotopologues of water molecules is the formation of density inhomogeneities, i.e., deuterium-stabilized gigantic heterophase clusters.

3. Biological effects of the light water are not related to the ligand-dependent toxic effect, but determined by the adaptive reasons. 


\section{References}

[1]. Ferronskii, V.I. and Polyakov, V.A., Izotopiya Gidrosfery (Isotopy of Hydrosphere), Moscow: Nauka, 1983.

[2]. Craig, H. Science. 1961, 133, 1833-1834.

[3]. Augustin, L., Barbante, C., Barnes, P.R.F. et al. Nature. 2004, 429, 623-628.

[4]. Hagemann, R., Niff, G., and Roth, E. Tellus. 1970, 22(6), 712-715.

[5]. De Wit, J.C., van der Straaten, C.M., and Mook, W.G. Geostandards Newsletter.1980, 4(1), 3336.

[6]. Krempels, K., Somlyai, I., and Somlyai, G. Integr. Cancer Ther. 2008, 7(3), 172-181.

[7]. Somlyai, G. Biokemia. 2007, 31, 28-32.

[8]. Somlyai, G. and Jancso, G. FEBS Lett., 1993, 7(1), 344-366.

[9]. Pricope, F., Stefanescu, I., Titescu, G. et al. Environ. Chem. Lett. 2003, 1(2), 149-151.

[10]. Goncharuk, V.V., Lapshin, V.B., Burdeynaya T.N. et al. Khimiya i Tekhnol. Vody. 2011, 33(1), 15-25.

[11]. Krasovskii, P.A., Karpov, O.V., Balakhanov, D.M. et al. Izmerit. Tekhn. 2010, 8, 16-20.

[12]. Syroeshkin, A.V., Popov, P.I., Grebennikova, T.V. et al., J. Pharm. Biomed. Anal. 2005, 37(5), 927-930.

[13]. Korostyshevskii, I.Z., Demikhov, Yu.N., and Berezovskii, F.I. Isotopenpraxis. 18(1), 10-15,

[14]. Lis, G., Wassenaar, L.I., and Hendry, M.J. Anal. Chem. 2008, 80(1), 287-293.

[15]. Gordon, A. and Ford, R. Sputnik khimika (Chemist Guide), Moscow: Mir, 1976.

[16]. Babizhayev, M.A., Nikolayev, G.N., Goryachev, S.N. et al. Biochim. Biophys. Acta. 2002, 1598, $46-54$.

[17]. Karmazina, T.V., Slisenko, V.I., Vasil'kevich, A.A. et al. Khimiya i Tekhnol. Vody. 2002, 24(2), $109-119$.

[18]. Galkin, M.A. and Syroeshkin, A.V. Biokhimiya. 1999, 64(10), 1393-1403.

[19]. Corcelli, S.A., Lawrence, C.P., and Skinner, J.L. J. Chem. Phys. 2004, 120(17), 8107-8117.

[20]. Lappi, S.E., Smith, B., and Franzen, S. Spectrochim. Acta, A. 2004, 60, 2611-2619.

[21]. Goncharuk, V.V., Smirnov, A.N., Lapshin, V.B. et al. Khimiya i Tekhnol. Vody. 2005, 27(2), $111-137$.

[22]. Goncharuk, V.V., Syroeshkin, A.V., Smirnov, A.N. et al. Vest. Ros. Un-ta Druzhby Narodov, Ser. Meditsyna. 2006, 2(34), 90-94.

[23]. Syroeshkin, A.V., Smirnov, A.N., Goncharuk, V.V. et al. Elektron. Zhurn. "Issledovano v Rossii”. 2006, 88, 843-854.

[24]. Goncharuk, V.V., Uspenskaya, E.V., Syroeshkin, A.V. et al. Farmatsiya. 2007, 5, 21-23.

[25]. Kuznetsov, D.M., Smirnov, A.N., and Syroeshkin, A.V. Ros. Khim. Zhurn. 2008, 52(1), 114-121.

[26]. Ul'yantsev, A.S., Uspenskaya, E.V., Pleteneva, T.V. et al. Khim.-Farm. Zhurn. 2009, 43(11), 47-51.

[27]. Fesenko, E.E. and Terpugov, E.L. Biofizika. 1999, 44(1), 5-9.

[28]. Ponomarev, O.A., Zakir'yanov, F.K., Terpugov, E.L. et al. Ibid. 2001, 46(3), $402-407$. 